\title{
ESTRATEGIAS TECNOLÓGICAS EN LA DESEMBOCADURA DEL RÍO SANTA CRUZ, PATAGONIA MERIDIONAL, ARGENTINA
}

DANIELA S. CAÑETE M. ${ }^{\text {a }}$

\begin{abstract}
RESUMEN
Las estrategias tecnológicas son planes utilizados para enfrentarse a los constreñimientos ambientales y sociales que evidencian las decisiones humanas. En este trabajo se busca conocer aquellas decisiones tecnológicas desarrolladas por los grupos humanos que habitaron Punta Entrada (Santa Cruz, Argentina) durante el Holoceno tardío y en este contexto evaluar la relación entre la tecnología, la caza y el procesamiento de los pinnípedos. Para ello, se analizó el material proveniente de las concentraciones a cielo abierto denominadas Punto 37 y 96 . Dicho material fue estudiado tecnomorfológicamente para luego ser analizado mediante test de estadística descriptiva a fin de obtener datos cuantitativos sobre la tecnología lítica. Como resultado, se pudo observar que la estrategia tecnológica predominante en ambos conjuntos es la expeditiva y que el equipo tecnológico está compuesto mayoritariamente por instrumentos de procesamiento confeccionados con materias primas inmediatamente disponibles y locales.
\end{abstract}

PALABRAS CLAVES: tecnología lítica, cazadores-recolectores, pinnípedos, ocupaciones costeras, estrategias tecnológicas.

\section{TECHNOLOGICAL STRATEGIES AT THE SANTA CRUZ RIVER MOUTH, SOUTHERN PATAGONIA, ARGENTINA}

\begin{abstract}
Technological strategies are known to be plans used by humans to deal with the environmental as well as social constraits which express human decisions. The main goal of this research is to understand the technological decisions of human groups who occupied Punta Entrada (Santa Cruz, Argentina) during Late Holocene. In this context, the relationship among technology, hunting and butchering of pinnipeds is evaluated. To achieve this objective, the archaeological remains from open scatters Punto 37 and 96 were analyzed. These assemblages were studied techno-morpologically and then were processed by test of descriptive statistics. The results obtained indicate that the
\end{abstract}


expedient strategy is dominant and that the technological gear is mainly composed of processing tools mamufactured on local and immediately available lithic raw materials.

KEY WORDS: lithic technology, hunter-gatherers, pinnipeds, coastal occupations, technological strategies

\section{INTRODUCCIÓN}

El objetivo principal de este trabajo es aportar información sobre la tecnología lítica de la costa meridional de la Patagonia y discutir acerca de las estrategias tecnológicas utilizadas por los cazadores-recolectores durante el Holoceno tardío en la margen sur de la desembocadura del río Santa Cruz, Argentina. Para ello, se ha trabajado con el material lítico recuperado en la localidad arqueológica de Punta Entrada, específicamente con aquel proveniente de las concentraciones a cielo abierto denominadas Punto 37 y 96 . Aquí se presentan y discuten los resultados obtenidos a partir del análisis de dicho material.

EnPuntaEntradase han detectado numerosas concentraciones de material arqueológico a cielo abierto caracterizadas por la presencia de grandes cantidades de restos zooarqueológicos (Muñoz et al. 2013), asociados a material lítico y restos malacológicos. Los investigadores que trabajan en esta área han descripto una preponderancia de restos de pinnípedos por sobre otros animales (Muñoz et al. 2009, Cruz et al. 2010b, 2011a, Muñoz et al. 2013). Como resultado del análisis de dichos restos, estos sectores han sido definido como puntos del espacio en los cuales se realizaban tareas de caza y procesamiento de pinnípedos de las especies Otaria flavescens y Arctocephalus australis. Sin embargo, para poder completar este panorama es necesario evaluar la tecnología lítica que acompaña este registro.

En este trabajo se desarrolla el análisis de esos conjuntos líticos siguiendo los lineamientos teóricos propuestos por el enfoque de la organización tecnológica (sensu Nelson, 1991) ya que ha mostrado ser un instrumento teórico útil para analizar temas tales como el uso del espacio y las estrategias tecnológicas desarrolladas por las poblaciones en el pasado. Este enfoque permite conocer los modos o planes utilizados por los grupos humanos para la resolución de diversas situaciones a las que los enfrenta el medio ambiente
(Binford, 1979; Nelson, 1991; Andrefsky, 1994; Carr, 1994a, 1994b; Odell, 1994; Castro et al. 2000; Espinosa, 2002; Franco, 2004; Escola 2004, entre otros).

\section{PUNTA ENTRADA: UBICACIÓN GEOGRÁFICA Y AMBIENTE}

La localidad arqueológica de Punta Entrada está ubicada sobre la costa atlántica en la margen sur de la desembocadura del río Santa Cruz, provincia de Santa Cruz, Argentina (50 $\left.08^{\prime} \mathrm{S}-68^{\circ} 22^{\prime} \mathrm{O}\right)$, a unos pocos kilómetros del puerto de Punta Quilla y de la ciudad de Puerto Santa Cruz (ver Fig. 1). Este sector del espacio es una zona de acumulación dentro del recorrido del río, el cual está constituido por cordones litorales (Kokot, 2004).

Punta Entrada es un territorio de acreción marino litoral de 220 ha que se encuentra constituido por grupos de cordones litorales gravo-arenosos enmarcados por un acantilado inactivo. Este último está disectado por amplios cañadones originados a causa de la acción fluvial (Del Valle \& Kokot, 1998; Cruz et al. 2010b, 2011a; Ercolano, 2012). Allí, se ha detectado un paleosuelo de 3.550 años AP sobre depósitos arenosos que cubren los cordones litorales más antiguos (Cruz et al. 2012). La vegetación de esta localidad, que pertenece al ambiente salino, se caracteriza por una estepa arbustiva baja del tipo de los eriales y la fauna silvestre, tanto marina como terrestre, es abundante (Del Valle \& Kokot, 1998, Cruz et al. 2010b, 2011a). Cabe destacar que varias especies animales cumplen su ciclo reproductivo en la localidad (Cruz et al. 2010b), como por ejemplo, pingüinos de Magallanes (Spheniscus magallanicus).

\section{LAS CONCENTRACIONES ANALIZADAS: PROCEDENCIA DE LOS MATERIALES E INFORMACIÓN ARQUEOLÓGICA PREVIA}

El material arqueológico considerado para este trabajo procede de las concentraciones 

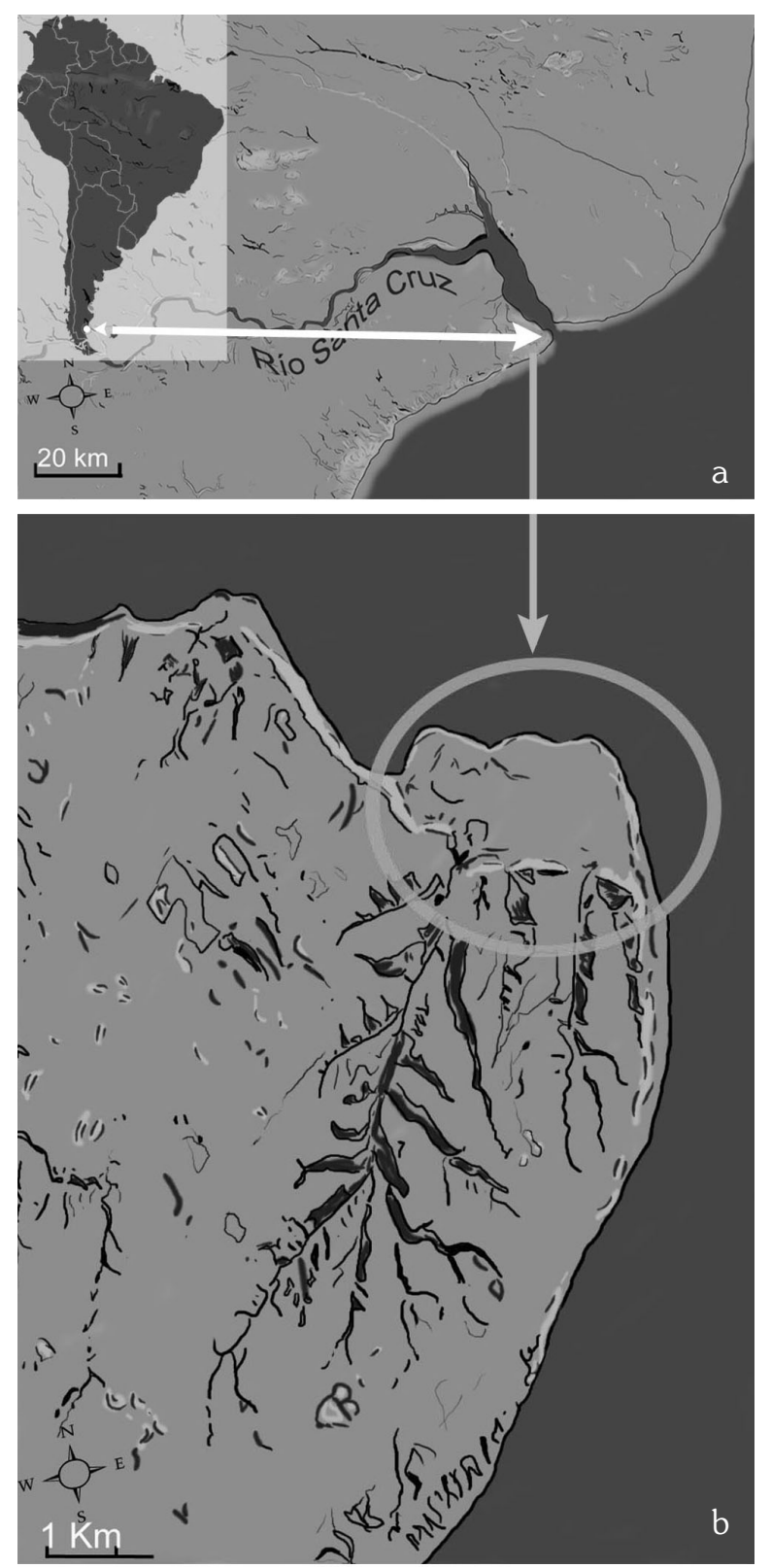

Fig. 1. Ubicación geográfica de Punta entrada. a: desembocadura del río Santa Cruz, b: Punta Entrada.

denominadas Punto 96 y Punto 37 (P 37 y P 96 de aquí en más). Ambos loci se definen por ser grandes concentraciones de material expuesto, en las cuales se realizaron recolecciones superficiales de manera sistemática por medio de cuadrículas de $2 \times 1 \mathrm{~m} \mathrm{y}$ en el caso del Punto 37 esto fue complementado con la excavación de una cuadrícula de $1 \mathrm{~m}^{2}$. Los materiales se encontraban depositados sobre sedimentos eólicos suprayacentes a los cordones litorales que conforman Punta Entrada. Estas concentraciones de material arqueológico, si bien poseen restos malacológicos, no constituyen concheros.

P 37, datado en $1.570 \pm 70$ años AP con corrección por efecto reservorio estimado en 1.138 \pm 70 años AP (Muñoz et al. 2009), corresponde a un depósito arqueológico a cielo abierto de $36 \mathrm{~m}^{2}$ de extensión. Esta concentración se encontraba previamente contenida en un médano, el cual fue perdiendo matriz arenosa por erosión eólica generando la exposición del material arqueológico. Se encuentra ubicado sobre un acantilado activo de $1,5 \mathrm{~m}$ de altura aproximadamente, muy cercano a la línea actual de mareas (Ver Fig. 2. Muñoz et al. 2009, 2013).

Por su parte, P 96 fue datado en $1.330 \pm 100$ años AP con corrección por efecto reservorio estimado en $930 \pm 100$ años AP, $1.750 \pm 80$ años AP y $2.050 \pm 110$ años AP con corrección por efecto reservorio en $1.750 \pm 110$ años AP (Muñoz et al. 2009, Cruz et al. 2010b). Esta concentración es un depósito en superficie localizado en una zona de médanos a 500 m de la costa actual (Ver Fig. 3) y cuya extensión es de aproximadamente $200 \mathrm{~m}^{2}$ (Cruz et al. 2015).

A partir del análisis de los restos zooarqueológicos, específicamente de los restos de pinnípedos, se han observado algunas semejanzas $y$ diferencias entre ambas concentraciones. Dentro del conjunto proveniente de P 37 se han registrado estadios de meteorización más altos que los hallados en P 96 lo cual informa acerca de historias tafonómicas diferentes. En relación a la proporción de huesos con marcas antrópicas, se ha observado que es semejante entre ambos conjuntos (alrededor del 10\%). Otra semejanza radica en la representación anatómica de estos animales. Pero las categorías anatómicas muestran que la representación del miembro anterior es diferente entre ambos conjuntos, ya que en P 37 es significativamente más elevada $(22 \%$ de miembros anteriores) que la de las demás regiones de este mismo conjunto y de todas las regiones en $\mathrm{P} 96$ (menos de $8 \%$ de miembros anteriores) (Muñoz et al. 2013).

Otras diferencias que se pueden mencionar entre estas dos concentraciones, es que las 


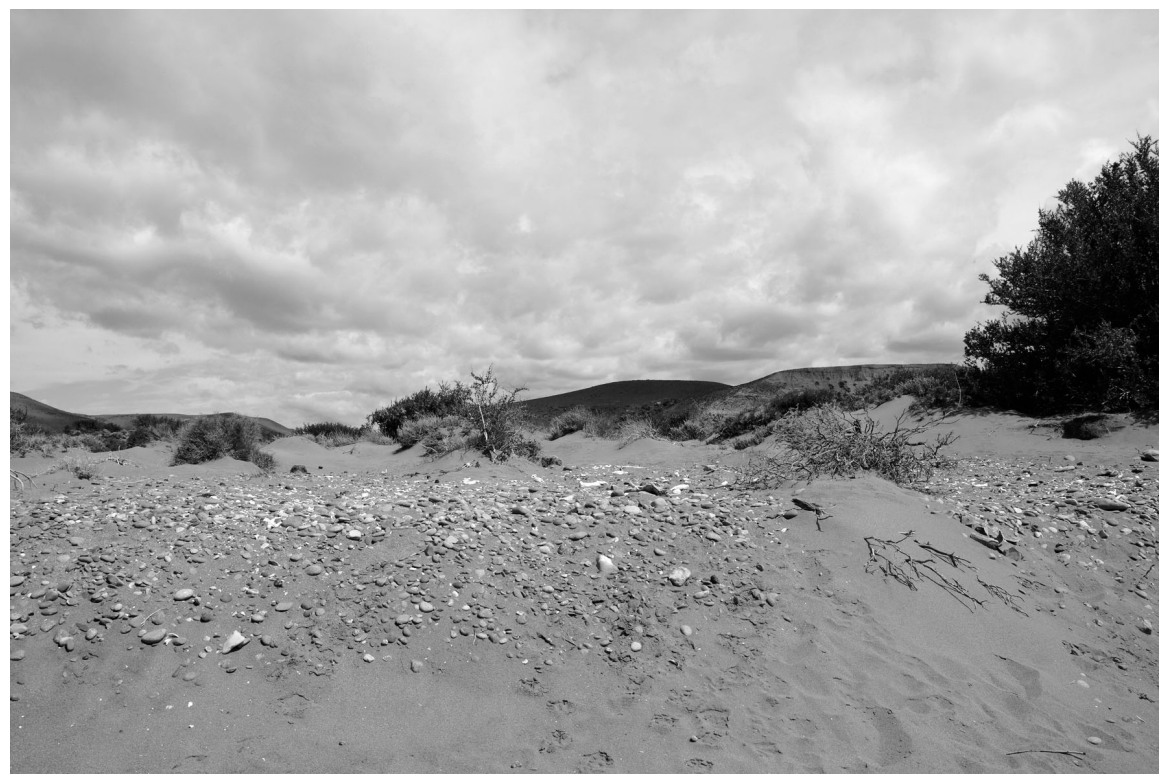

Fig. 2. Estado actual del Punto 37.

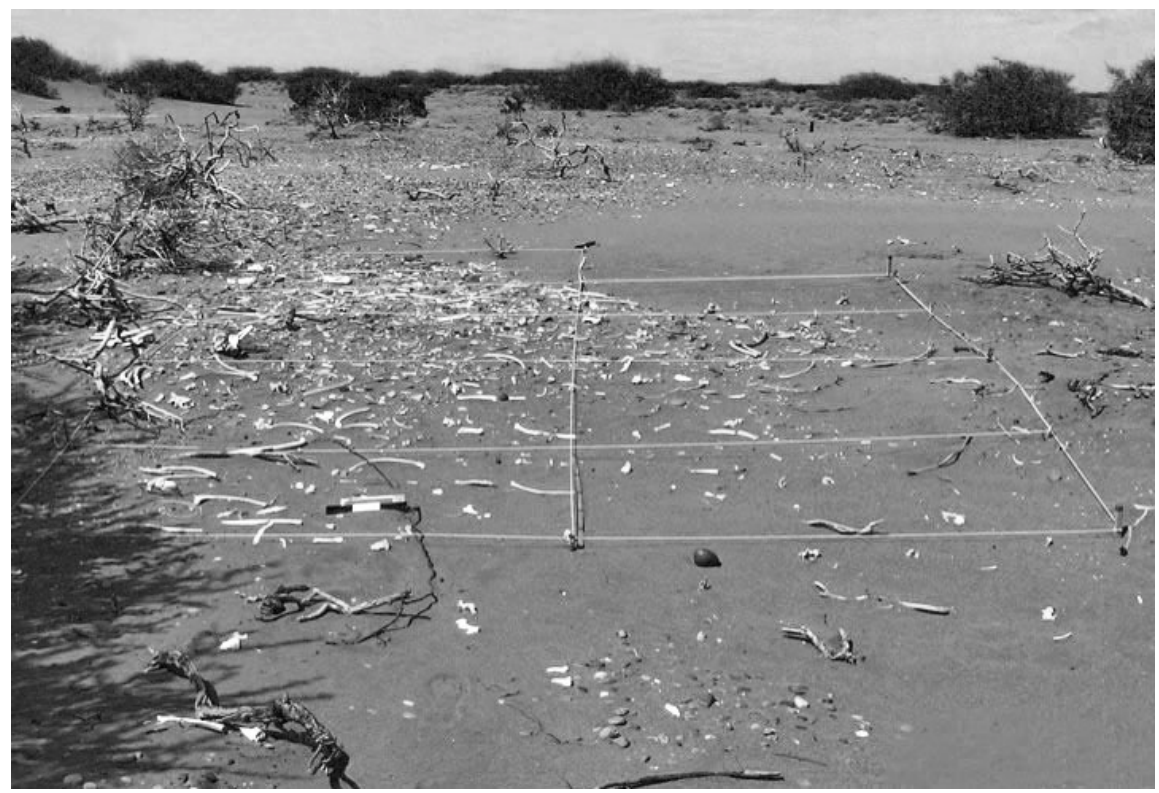

Fig. 3. Punto 96.

carcasas de P 37 se encuentran menos completas que en $\mathrm{P} 96$ y que en el primero la representación de individuos inmaduros es más baja. Así, en P 37 éstos alcanzan un $17 \%$ del total de los pinnípedos (Cruz et al. 2011a; Buc \& Cruz, 2012; Muñoz et al. 2013), mientras que en $P 96$ se ha registrado un $61 \%$ de este grupo etario. Estas evidencias han permitido inferir que en P 37 los cazadores- recolectores no habrían realizado una selección de un determinado grupo etario. En dicho Punto hay una baja representación de aletas y una sobre-representación de miembros delanteros, lo cual no sucede en $\mathrm{P} 96$, donde la relación entre cabezas y miembros es próxima a la que se encuentra en individuos completos. Esto sugiere que las presas habrían estado completas en P 96 
y que determinados comportamientos como el procesamiento y el descarte diferencial podrían haber afectado la compleción de las carcasas transportadas (Muñoz et al. 2013). Por otro lado, en P 37 se ha observado un bajo nivel de integridad anatómica resultado de una predominancia de húmeros y escápulas dentro del conjunto, lo cual dificulta la interpretación de este registro (Muñoz et al. 2013).

Finalmente, se puede mencionar que en P 96 se registró una gran diversidad de partes esqueletarias y la presencia de elementos con distintos valores económicos, lo cual estaría evidenciando el procesamiento de estos animales en un lugar muy próximo a dicho apostadero (Cruz et al. 2011a). Es a partir de dicha información que los investigadores propusieron un uso diferencial de la costa a lo largo del año y a su vez una explotación diferencial de los recursos a lo largo de la costa (Cruz et al. 2010b; Muñoz et al. 2013). Esta información se ve reforzada por la incongruencia que aparece entre los datos isotópicos de restos humanos hallados en la localidad ya que sugieren el predominio de dieta terrestre (Suby et al. 2009; Cruz et al. 2010b, 2011a). Relacionado a esta situación, merece mencionarse la presencia de materias primas líticas alóctonas, como es el caso de la obsidiana negra de Pampa del Asador (de los tipos PDA I, PDA II y PDA III), la obsidiana gris verdosa veteada del Cordón de Baguales, la obsidiana verde del Seno de Otway y la obsidiana gris del Chaitén (Cruz et al. 2010a, 2011b; Stern et al. 2012). Asimismo, se han observado artefactos de obsidianas aún indeterminadas (Cañete Mastrángelo, 2015). Finalmente, otra evidencia que muestra el contacto de estos grupos con otros ambientes (circulación de objetos y/o personas) es la presencia de un artefacto de asta de huemul (Cruz et al. 2010a).

$\mathrm{Al}$ ser $\mathrm{P} 96$ un posible apostadero, se puede inferir que el recurso resultaba predecible y disponible para la población humana. Siguiendo esta línea de pensamiento, podría plantearse que por lo menos en cuanto a la forma natural en la que se presentaban tales recursos, existiría una situación de bajo estrés sobre los mismos implicando que los grupos humanos no necesitaban actuar de manera más precisa y rápida. Por otra parte, dada la proximidad de los sitios al cordón litoral, se puede decir que las materias primas se encontrarian ampliamente disponibles para su aprovechamiento en las fuentes inmediatas.

\section{EL MATERIAL LÍTICO DE LOS PUNTOS 37 Y 96}

El conjunto tecnológico fue analizado y clasificado siguiendo la propuesta de Aschero (1975, 1983), Aschero y Hocsman (2004) y Bellelli et al. (1985). En el caso de las materias primas, la determinación fue realizada de manera macroscópica en base a la observación personal (noviembre 2011, 2015) y al análisis de la bibliografía geológica y arqueológica de áreas circundantes a la zona de interés (Fidalgo \& Riggi, 1970; Aragón \& Franco, 1997; Borrero et al. 2008; Caracotche et al. 2008; Franco \& Cirigliano, 2009; Cardillo, 2009).

En P 37 se ha recuperado un total de 443 artefactos, de las cuales 319 provienen de la recolección superficial (RS) y comprenden: 313 desechos de talla y seis instrumentos. Del contexto de excavación (EXC) provienen 127 piezas: 123 son desechos de talla, tres son instrumentos y la restante es un núcleo. Por su parte, en $\mathrm{P} 96$ se han recuperado un total de 287 artefactos, de las cuales 259 son desechos de talla, 17 son instrumentos y 10 son núcleos.

\section{Núcleos}

La presencia de núcleos es muy dispar entre ambos loci. En P 37 sólo se ha encontrado un núcleo de forma poliédrica confeccionado sobre RGFO (roca de grano fino oscura (sensu Charlín 2005). Exceptuando el basalto, que pudo ser diferenciado), en cambio, en $\mathrm{P} 96$ se han recuperado 10 núcleos que presentan formas diferentes, principalmente los de forma discoidal irregular o parcial y que fueron confeccionados en diversas materias primas siendo predominantes los de dacita. El núcleo de $\mathrm{P}$ 37 se encuentra agotado mientras que los de P 96 presentan tamaños que habrían permitido realizar más extracciones (ver Tabla 1).

Desechos de talla

Se ha observado una gran variedad de 


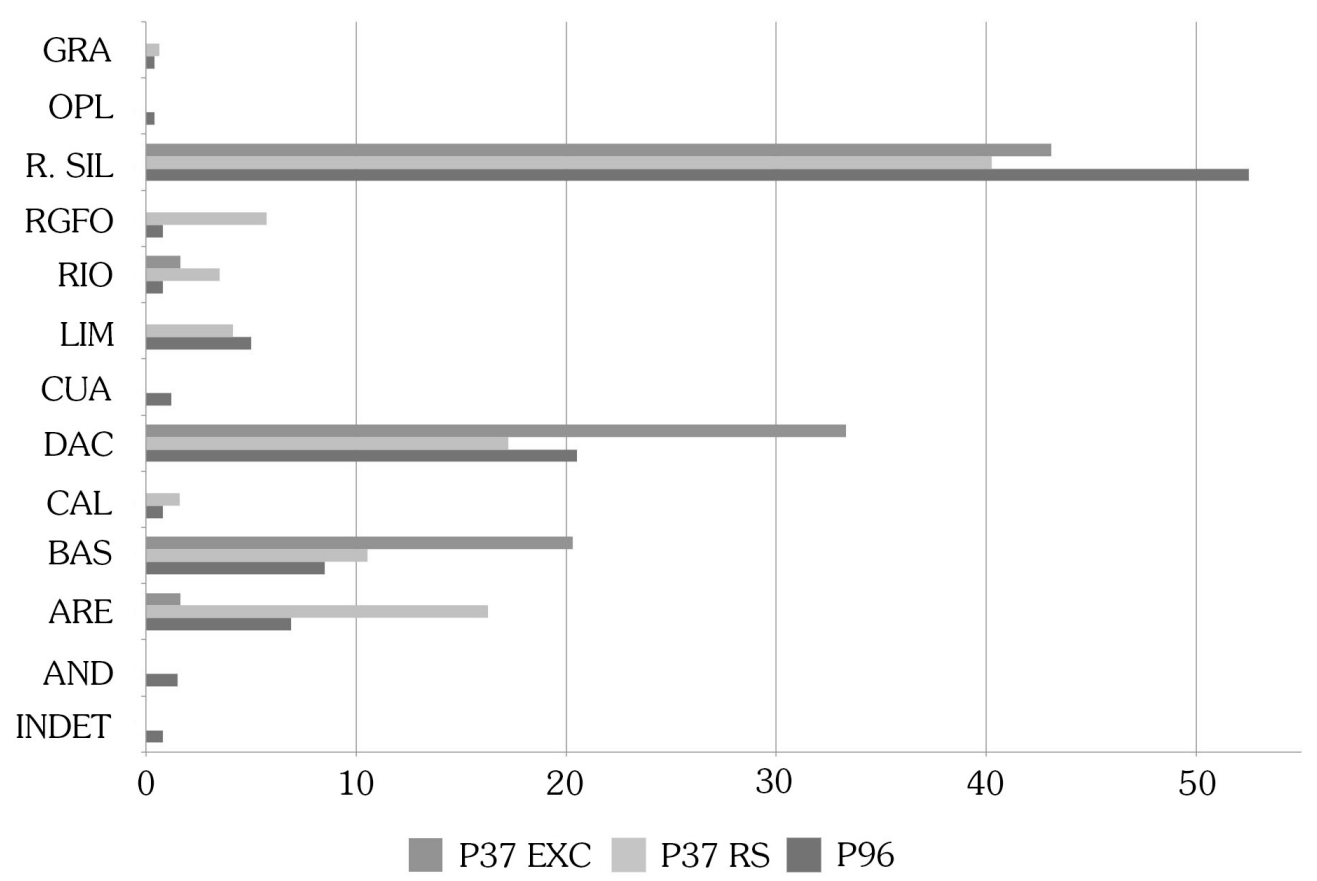

Figura 4. Gráfico comparativo de la representación de las materias primas en los tres conjuntos analizados. $\mathrm{GRA}=$ Granito, $\mathrm{OPL}=$ Ópalo, $\mathrm{R} . \mathrm{SIL}=$ Rocas silíceas, $\mathrm{RGFO}=$ Roca de grano fino oscura, $\mathrm{RIO}=$ Riolita, $\mathrm{LIM}=$ Limolita, $\mathrm{CUA}=$ Cuarcita, $\mathrm{DAC}=$ Dacita, $\mathrm{CAL}=$ Calcedonia, $\mathrm{BAS}=$ Basalto, $\mathrm{ARE}=$ Arenisca, $\mathrm{AND}=$ Andesita, INDET= Indeterminada.

materias primas dentro del conjunto de desechos de talla de las concentraciones analizadas. Las rocas silíceas son la materia prima más frecuente, llegando a alcanzar más del $50 \%$ en las piezas provenientes del grupo RS de P 37. La segunda en importancia es la dacita (Fig. 4). El basalto, el cual en este trabajo se excluye de la categoría RGFO y la arenisca, aunque en menor número, se destacan en todas las muestras.

En cuanto al tipo de lasca, también se puede observar una gran variedad dentro de toda la muestra. Las lascas angulares son las predominantes en los tres conjuntos estudiados. Se registraron lascas correspondientes a toda la secuencia de la reducción lítica, desde las primarias hasta las de reactivación directa. Estas últimas sólo fueron registradas en el grupo de recolección superficial de $\mathrm{P} 37$ mientras que las que presentan reserva de corteza fueron recuperadas en todos los conjuntos. Finalmente, cabe destacar la existencia de lascas relacionadas

1 De acuerdo a lo convenido en el Taller "Morfología macroscópica en la clasificación de los artefactos líticos" con la limpieza y reactivación de núcleos como son las lascas tableta de núcleos y flanco de núcleo, ambas con mayor presencia en P 96 (ver Tabla 1).

Los distintos estadios de talla también pueden observarse a través de los tamaños de las lascas (Espinosa, 1995, 1998; Guraieb \& Espinosa, 1998, entre otros), por esta razón se ha analizado el módulo de tamaño de las lascas enteras. Se ha observado que los tamaños pequeño y mediano-pequeño aparecen en los tres conjuntos. Los muy pequeños sólo fueron registrados en $\mathrm{P} 37$ ( $\mathrm{RS}$ y EXC), pero debe tenerse en cuenta que al tratarse de concentraciones a cielo abierto, la presencia de lascas de este tamaño puede verse alterada por diversos agentes naturales (Borrazzo, 2006). El tamaño muy grande sólo fue recuperado en P 96 (ver Tabla 2).

En las tres concentraciones estudiadas se han registrado lascas con reserva de corteza del 
Tabla 1. Tipos de lascas observados en los conjuntos analizados. T.N. = Tableta de núcleo, SEC.$=$ Secundaria, R.D.= Reactivación directa, PRI.$=$ Primaria, $\mathrm{POL} .=$ Poliedro, INDIF.$=$ Indiferenciada, F.N.= Flanco de núcleo, D.N.= Dorso natural, $\mathrm{BIPOLAR}=$ Producto bipolar, AR. $=$ Arista, $\mathrm{AN} .=$ Angular.

\begin{tabular}{cccc}
\hline $\begin{array}{c}\text { TIPO DE } \\
\text { LASCA }\end{array}$ & P37 RS\% & P37 EXC\% & P96\% \\
\hline TN. & 0,65 & 0 & 2,1 \\
SEC. & 5,88 & 16,13 & 9 \\
R.D. & 0,65 & 0 & 0 \\
PRI. & 5,23 & 3,23 & 2,1 \\
POL. & 1,31 & 6,45 & 0,7 \\
PLANA & 7,84 & 19,35 & 13,1 \\
INDIF. & 0,65 & 0 & 0 \\
F.N. & 0,65 & 0 & 1,4 \\
D.N. & 2,61 & 22,58 & 9 \\
BIPLOAR & 1,31 & 0 & 1,4 \\
AR. & 2,61 & 16,13 & 4,1 \\
AN. & 70,59 & 61,29 & 57,2 \\
\hline
\end{tabular}

$25 \%$ o más de su superficie ${ }^{1}$. Esta situación es más abundante en P 96, en la cual las lascas con reserva de corteza alcanzan en $28,40 \%$. La presencia de corteza también ha sido detectada sobre los talones de las lascas de todos los conjuntos estudiados, siendo más importante en P 96 (ver Tabla 2).

Finalmente, se analizaron los talones y los bulbos. Dentro de los talones, los que predominan en todos los conjuntos estudiados son los lisos. En ambas concentraciones también se ha registrado la presencia de varios tipos de talones, a excepción de los puntiformes y diedros que se encuentran ausentes entre los desechos de talla del grupo EXC de P 37. Asimismo se han registrado diferencias en cuanto a la frecuencia en la que aparece cada uno de los tipos de talones en las concentraciones estudiadas. En P 96 se registraron todos los tipos e incluso se observaron casos en los que el talón no pudo ser identificado a pesar de que el desecho estaba entero. Esta situación no se percibió en ningún

Tabla 2. Resumen de datos provenientes de los desechos de talla y de los núcleos de los tres conjuntos estudiados -P37 grupos RS y EXC y P96-. El valor de los núcleos fue calculado sobre el total de la muestra.

\begin{tabular}{lccc} 
& \multicolumn{2}{c}{ PUNTO 37} & PUNTO $96 \%$ \\
\hline TAMAÑO MUY PEQUEÑO & RS & EXC $\%$ & 0 \\
TAMAÑO PEQUEÑO & 10,53 & 50 & 13,16 \\
TAMAÑO MEDIANO-PEQUEÑO & 39,47 & 33,33 & 26,32 \\
& 28,95 & 16,67 & \\
TAMAÑO MEDIANO-GRANDE & & & 23,28 \\
TAMAÑO GRANDE & 10,53 & 0 & 18,42 \\
TAMAÑO MUY GRANDE & 10,53 & 0 & 18,42 \\
LASCAS INTERNAS & 0 & 0 & 71,60 \\
& 80,52 & 85,37 & 28,40 \\
LASCAS CON CORTEZA (>25\%) & 19,48 & 14,63 & 48,28 \\
TALÓN LISO & 43,14 & 77,42 & 17,24 \\
TALÓN COTICAL & 12,42 & 3,23 & 6,21 \\
TALÓN FILIFORME & 7,19 & 3,23 & 4,83 \\
TALÓN PUNTIFORME & 7,84 & 0 & 3,45 \\
TALÓN FACETADO & 15,03 & 3,23 & 3,45 \\
TALÓN DIEDRO & 2,61 & 0 & 3,52 \\
NÚCLEOS & 0 & 0,79 & \\
\hline
\end{tabular}




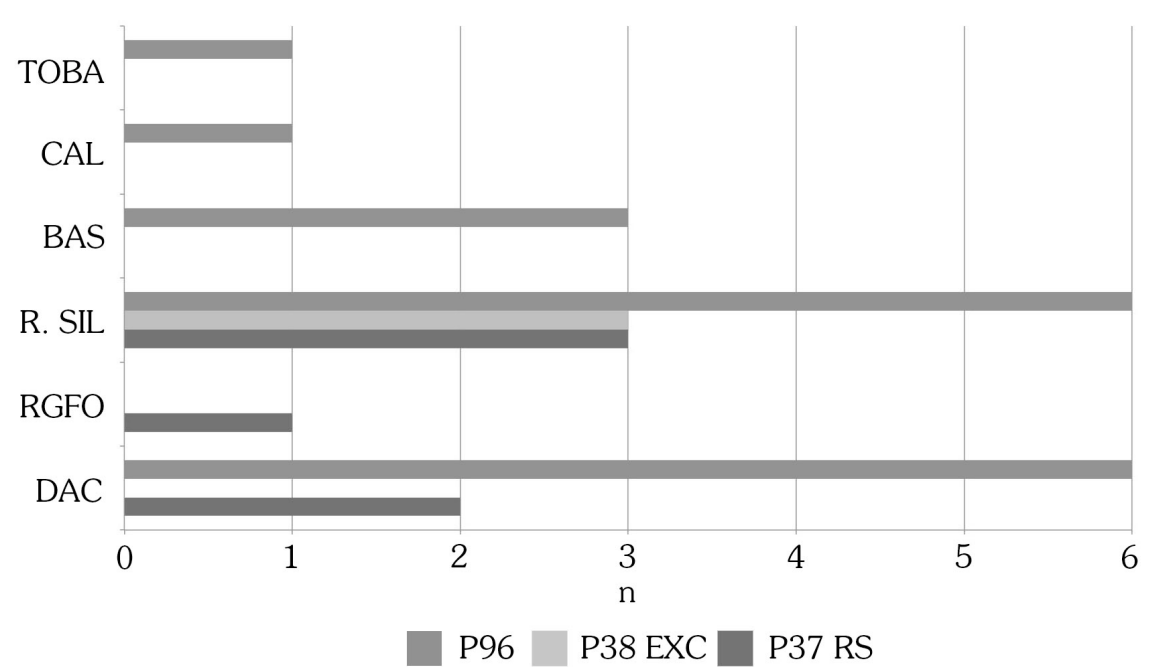

Fig. 5. Materias primas sobre las que fueron confeccionados los instrumentos de los tres conjuntos estudiados. $\mathrm{CAL}=$ Calcedonia, $\mathrm{BAS}=$ Basalto, $\mathrm{DAC}=$ Dacita, $\mathrm{R} . \mathrm{SIL}=$ Rocas silíceas.

grupo de P 37 (ver Tabla 2).

La situación de los bulbos también es distinta entre ambas concentraciones. Si bien se han observado los tres tipos (indiferenciado, difuso y pronunciado) tanto en una concentración como en la otra, en P 37 la distribución de cada uno es menos pareja que en $\mathrm{P} 96$, donde la diferencia en la frecuencia de los tipos de bulbo es menos marcada. Los conjuntos de P 37 presentan bulbos predominantes distintos. En el caso del grupo proveniente de la recolección superficial los difusos son los mayoritarios y en el conjunto estratigráfico lo son los indiferenciados, lo mismo que se observa en P 96. En todos los conjuntos los bulbos pronunciados son los menos frecuentes.

\section{Instrumentos}

Las materias primas observadas dentro de la muestra que corresponde a los instrumentos son las mismas que las registradas en los desechos de talla a excepción de la toba, que sólo fue registrada en un instrumento. Tal como puede observarse en la Fig. 5, la materia prima predominante también son las rocas síliceas.

Para presentar los grupos tipológicos registrados se ha decidido trabajar con el total de filos ( $P 37$ RS N=10, P 37 EXC N=4 y P $96 \mathrm{~N}=25$ ) ya que existen algunos casos en los cuales una pieza presenta más de un filo. Este análisis permitió observar que las raederas están presentes en todos los conjuntos (P $37 \mathrm{RS}=40 \%$, P $37 \mathrm{EXC}=25 \%, \mathrm{P}$ 96=28\%). Los raspadores (P $37 \mathrm{EXC}=25 \%, \mathrm{P} 96=20 \%$ ) y los artefactos de formatización sumaria ( $\mathrm{P} 37 \mathrm{RS}=10 \%$, $\mathrm{P}$ $96=40 \%$ ) están presentes en ambos loci pero no en todos los conjuntos.

Los grupos tipológicos relacionados exclusivamente con P 37 son la punta burilante (10\%) y el biface (30\%) que fueron hallados en P 37 RS. Por otra parte, se han identificado fragmentos de filo no diferenciado ( $\mathrm{P} 37$ $\mathrm{RS}=10 \%$, P $37 \mathrm{EXC}=25 \%$ ) en ambos contextos de recuperación. $\mathrm{P} 96$ se diferencia por la presencia de cortantes o trinchetas (4\%) y de filos en bisel oblicuo mediano-pequeños/muy pequeños ( $\mathrm{RBO}, 8 \%$ ).

En cuanto a los tamaños, en P 37 RS se ha recuperado un solo instrumento entero, de tamaño grande pero en P 37 EXC no se ha detectado ninguna pieza entera, con lo cual no se pudo obtener la información suficiente para la evaluación de dicha variable. En P 96 se detectó la presencia de varios tamaños, siendo el grande el mayoritario $(\mathrm{N}=4)$, seguido por el muy grande $(\mathrm{N}=3)$ y finalmente los pequeños, mediano-pequeños y mediano-grandes $(\mathrm{N}=1$ en cada caso). Esta preponderancia coincide con el observado en el único instrumento entero 
recuperado en $\mathrm{P} 37$.

Otra variable analizada dentro de los artefactos formatizados es la presencia de corteza, la cual se manifiesta de forma diferente en los tres conjuntos. En el grupo RS de P $37(\mathrm{~N}=6)$ se ha observado que la mitad de los instrumentos presentan reserva de corteza. Por su parte, los instrumentos provenientes del contexto estratigráfico $(\mathrm{N}=3)$ no presentan dicha característica. A diferencia de todo esto, en P 96 la mayoría de los instrumentos $(\mathrm{N}=11)$ registran reserva de corteza. Resulta destacable que en ambos loci la presencia de corteza tanto en instrumentos como en desechos de talla se manifiesta en porcentajes considerables (ver Tabla 2).

Para evaluar el uso de las materias primas se ha observado la cantidad de filos por instrumentos y el estado del mismo. La presencia de más de un filo por pieza ha sido detectada en algunos instrumentos del grupo RS de P $37(\mathrm{~N}=2)$ y de P $96(\mathrm{~N}=4)$. En relación al estado del filo, se ha observado que en el contexto de recolección superficial, la mayor parte de los filos exhibe ángulos inferiores a $80^{\circ}(\mathrm{N}=8)$, tendencia que se invierte en el grupo proveniente del contexto de excavación ( $\mathrm{N}=1)$ y en el conjunto de $\mathrm{P} 96$, donde son los filos superiores a $80^{\circ}$ los que predominan en la muestra $(\mathrm{N}=13)$. Por lo tanto, en P 96 y en P 37 EXC predominan los filos embotados, lo que es opuesto a la situación que se registra en $\mathrm{P} 37 \mathrm{RS}$. Otra diferencia a señalar es que en $\mathrm{P} 96$ se ha percibido la presencia del estado embotado astillado, el cual no ha sido registrado en ninguno de los otros dos conjuntos estudiados.

\section{Filos naturales con rastros complementarios}

Los filos naturales con rastros complementarios sólo han sido recuperados hasta el momento en $\mathrm{P}$ 96. Se ha recuperado una sola pieza que presenta un filo natural con rastros complementarios en un instrumento que también presenta un filo de raspador y un artefacto de formatización sumaria. Esta pieza fue confeccionada sobre dacita. Este filo se encuentra activo, es decir, presenta un ángulo de filo inferior a $80^{\circ}$, la forma primaria del filo es normal regular. Sobre la superficie del filo se han observado ultramicrolascados adyacentes que podrían ser consecuencia de su uso.
A modo de resumen, puede mencionarse que los desechos de talla y los instrumentos fueron registrados en los tres conjuntos estudiados. Mientras que los núcleos sólo están presentes en P 37 EXC y P 96, siendo este último el que posee mayor cantidad de representantes de esta clase y el único donde se observaron filos naturales con rastros complementarios. En relación a las materias primas, las mayores diferencias fueron registradas entre ambos loci y no así entre ambos contextos de recuperación de P 37. P 37 EXC es el conjunto que presenta menor variabilidad, pero esto puede estar vinculado al tamaño de la muestra (es el más pequeño). La frecuencia de tamaños es variable entre todos los conjuntos, siendo el pequeño el que predomina en los desechos de talla de P $37 \mathrm{RS}$, el muy pequeños en los de P 37 EXC y el medianopequeño en los de P 96. Sin embargo, el tamaño grande es el que predomina en los instrumentos de P 37 RS y P 96. Las lascas internas son las de mayor importancia en todos los conjuntos aunque debe considerarse que la reserva de corteza no es menor si se toma en cuenta las piezas de todas las clases tipológicas y la presencia de talones corticales en varios desechos de talla.

Finalmente, en los tres conjuntos analizados se ha observado la presencia de raederas mientras que el resto de los grupos tipológicos descriptos fueron hallados en ambos loci pero no en ambos contextos de recuperación de P 37 (raspadores y artefactos de formatización sumaria) o exclusivamente en este último (punta burilante y biface) o en P 96 (cortantes o trinchetas y RBO). La presencia de más de un filo por pieza ha sido detectada en alguno de los instrumentos de P 37 RS y en los de P 96. Es en el primero donde tiene una mayor importancia, aunque se presenta de forma minoritaria en ambos loci.

\section{DISCUSIÓN}

Se ha observado que en ambas concentraciones los grupos humanos habrían realizado tareas relacionadas a los distintos momentos de la reducción lítica, los que abarcan desde el aprovisionamiento de las materias primas inmediatamente disponibles (sensu Civalero \& Franco, 2003). Siendo que amplia mayoría se encuentran disponibles en forma de rodados 
costeros en la proximidad de ambos Puntos (obs. pers. nov 2011, 2015), hasta los momentos finales de la producción de instrumentos e incluso pudo implicar también actividades de reactivación de filos. Estas inferencias pudieron realizarse a partir de los datos obtenidos del análisis de diversas variables, como son el tamaño (Espinosa, 1995, 1998, entre otros), el tipo de lasca (Aschero, 1975, 1983, Guraieb \& Espinosa, 1998), el tipo de talón (Bradbury \& Carr, 1999, Frank et al. 2007) y la reserva de corteza (Espinosa, 1998; Bradbury \& Carr, 1999), que se describen a continuación.

El conjunto lítico de P 37, tanto del contexto superficial como estratigráfico, está compuesto en su mayoría por desechos de talla de diversas materias primas. A pesar de las pocas piezas que se conservan enteras se pudo apreciar que los tamaños presentes en esta muestra van desde el muy pequeño hasta el grande, lo que puede relacionarse con la realización de diversos estadios de la reducción lítica en este Punto (ver Tabla 2). Por su parte, el conjunto de los desechos de talla de P 96 está compuesto por lascas que van desde el tamaño pequeño hasta el muy grande (ver Tabla 2), también confeccionados sobre diversas materias primas. Las lascas de tamaño muy pequeño (microlascas) suelen estar relacionadas a la formatización y/o reactivación de filos (Espinosa, 1995, 1998, entre otros). Por su parte, los tamaños grandes se vinculan con el comienzo de la secuencia productiva, lo que se estaría llevando a cabo en ambos sitios (Guraieb \& Espinosa, 1998). Frente a la ausencia de microlascas enteras en $\mathrm{P}$ 96 debe considerarse que el material fue obtenido mediante recolección superficial, distinto a lo que ocurre en P 37, donde se cuenta además con piezas provenientes de contexto estratigráfico (contexto del cual proviene la mayor parte de los desechos de este tamaño), lo cual implica que se utilizó una técnica distinta de recolección del material y que puede estar afectando la representación del tamaño muy pequeño en la muestra de P 96. Asimismo, es esperable que exista una ausencia de dicho tamaño en los conjuntos de superficie de los sitios costeros debido a la dinámica ambiental (Borrazzo, 2006).

Otro aspecto que apoya esta interpretación es la presencia en ambos Puntos de desechos de talla con talones lisos (ver Tabla 2), que se han vinculado al momento de la confección de los filos (Espinosa, 1995) y de talones filiformes y puntiformes, los cuales han sido relacionados con los resultados producidos por la talla por presión, una de las técnicas empleadas en el mantenimiento de los filos de los instrumentos (Espinosa, 1995). Estos talones exhiben una ligera predominancia en P 37 respecto de P 96 (ver Tabla 2). Se podría plantear, sobre la base de la predominancia en ambas concentraciones de talones lisos por sobre los filiformes y puntiformes, que las actividades relacionadas con la confección de filos habría sido más frecuente que las relacionadas al mantenimiento de los mismos (Espinosa, 1995). En el conjunto de superficie de P 37, los talones facetados exhiben una representación relativa importante (ver Tabla 2) que puede asociarse, entre otras cosas, a la presencia de estadios avanzados de la talla lítica (Bradbury \& Carr, 1999), lo que reforzaría la inferencia realizada en base a las variables anteriores.

El escenario propuesto sobre los posibles estadios de talla presentes en cada conjunto se ve complementado con la información aportada por los tipos de lascas (Guraieb \& Espinosa, 1998). En ambas concentraciones las lascas predominantes son las angulares que, junto con las demás lascas internas (ver Tabla 1) concentran una amplia mayoría de la muestra. Esto indicaría que el momento más representado es el correspondiente a la extracción de formas base y otras tareas del final de la secuencia operativa (Guraieb \& Espinosa, 1998). Otro dato de relevancia que apoya esta interpretación es la correlación entre las materias primas presentes en los desechos de talla y los instrumentos en ambos Puntos y entre dichas clases tipológicas y los núcleos en P 96. En esta última concentración, estas actividades fueron acompañadas por una etapa previa de la reducción lítica, la preparación de los núcleos, evidenciada por la presencia de lascas primarias, secundarias y de reactivación de núcleos, las que incluyen las de flanco de núcleos y las tableta de núcleos (Aschero, 1975, 1983; Guraieb \& Espinosa, 1998; Nami, 2006), por la presencia de talones corticales y lisos (Frank et al. 2007) y de desechos de talla con reserva de corteza (Espinosa, 1998; Bradbury \& Carr, 1999). A excepción de la presencia de núcleos, las evidencias descriptas precedentemente también fueron registradas en P 37, por lo que la 
posibilidad del desarrollo de las primeras etapas de reducción también deben ser consideradas para dicha concentración.

Finalmente, esta información puede complementarse con los datos aportados por el análisis en conjunto de las materias primas y la presencia de corteza. En ambas concentraciones se pudo apreciar que un porcentaje elevado de los desechos de talla de la mayor parte de las materias primas poseen reserva de corteza, lo cual permitiría postular que estas materias primas no fueron trasladadas desde grandes distancias (Bousman, 2005; Paulides, 2006) y refuerza la idea del desarrollo de las primeras etapas de la reducción lítica en las concentraciones estudiadas.

En términos generales se puede considerar que en P 96 la actividad de mayor importancia fue la relacionada a las primeras etapas de reducción como lo estaría mostrando la presencia de varios núcleos allí abandonados y la presencia de desechos de talla de tamaños grande y muy grande. Por el contrario, en $\mathrm{P} 37$ los núcleos aparecen mínimamente representados, sólo se ha recuperado una única pieza correspondiente a esta clase tipológica en el contexto estratigráfico. Alternativamente, la ausencia de núcleos en esta última concentración podría ser indicativa del transporte de tales artefactos a otros sectores del espacio.

\section{El uso de las materias primas en los Puntos 37 y 96}

El análisis realizado sobre la descripción tecno-morfológica y sobre las actividades tecnológicas desarrolladas por los grupos humanos en los Puntos 37 y 96 de Punta Entrada se ve complementado con la evaluación del modo en que las materias primas han sido utilizadas, ya que permite inferir distintos aspectos del comportamiento, tales como la movilidad y la inversión energética puesta en la confección de los instrumentos. En ambos conjuntos se ha definido la presencia de materias primas inmediatamente disponibles (sensu Civalero \& Franco, 2003) y locales (sensu Meltzer, 1989). Dada la proximidad y abundancia de la materia prima a los Puntos aquí trabajados, se puede plantear que éstas eran de fácil acceso y por lo tanto disponibles (sensu Andrefsky, 1994) para estos grupos, los cuales eligieron usar mayoritariamente aquellas inmediatamente disponibles (sensu Civalero \& Franco, 2003) en las distintas calidades en las que se presentan. El modo de obtención de las mismas habría sido directo (Ericson, 1984; Meltzer, 1989) desde fuentes secundarias (sensu Meltzer, 1989), ya que el aprovisionamiento se habría dado a partir de los rodados que se hallaban (y aún hoy se hallan) sobre la playa. La presencia de gran diversidad de materias primas dentro de los conjuntos (específicamente dentro de aquellos conformados por los desechos de talla de ambas concentraciones) también da sustento a la idea del uso de materias primas inmediatamente disponibles (Cardillo, 2009).

No se han registrado preferencias en el uso de alguna roca para la confección de algún grupo tipológico en particular. Por otro lado, se ha notado que el conjunto compuesto por los desechos de talla de ambas concentraciones presenta mayor diversidad de materias primas que aquellas determinadas para los instrumentos y los núcleos. Del mismo modo, es destacable la presencia de un instrumento de toba en $\mathrm{P}$ 96, materia prima que no ha sido detectada en ningún otro conjunto de ninguna de las dos concentraciones. Esto puede deberse a que se estuvieron tallando instrumentos que fueron abandonados en otro lugar y que también habrían ingresado piezas confeccionadas en otros puntos del espacio, como sería el caso del artefacto de formatización sumaria de toba. De todas formas, la mayor parte de las actividades tecnológicas se habrían llevado a cabo con las rocas inmediatamente disponibles.

En cuanto al manejo de las materias primas, los resultados sugieren una diferencia en el tratamiento de las rocas silíceas en comparación al resto. Esta materia prima presenta mayor diversidad de tipo de lascas marcando una mayor inversión energética en la confección de artefactos (Espinosa, 1995). Exhibe también piezas con más de un filo o punta activos en los instrumentos, bifaces, núcleos en $\mathrm{P} 96$ y representa la roca más utilizada para la confección de instrumentos. Si bien han sido utilizadas con mayor intensidad no se observó una relación directa entre el uso de las mismas con la confección de algún instrumento en particular. 
Estos elementos podrían estar mostrando que las rocas silíceas fueron preferidas por los talladores para la manufactura de los conjuntos tecnológicos posiblemente por causas que irían más allá de la disponibilidad y el fácil acceso que estos presentan y que podrían relacionarse con la mejor calidad que tienen para la confección de los instrumentos (MacDonald, 2008). Frente a esta situación en este trabajo se prefiere plantear un uso intensivo de estas rocas antes que una maximización de su uso dada la facilidad en el aprovisionamiento de esta materia prima. Esta situación contrasta con la planteada por Cardillo (2009) para la esta misma zona (desembocadura del río Santa Cruz), quien observa un uso predominante de dacita y de rocas oscuras de grano fino (ambas inmediatamente disponibles) para la confección de los instrumentos recuperados en sectores de la meseta adyacente a la costa, la playa de acreción y en el paleoacantilado de Punta Entrada. Tales materiales se encuentran asociados a acumulaciones de valvas y restos óseos, entre los que predominan los de guanaco y pinnípedo (Cardillo, 2009). Como se puede observar, el contexto del que provienen estos materiales es bastante parecido al de los materiales con los que aquí se trabaja, por lo cual es interesante resaltar esta diferencia registrada entre las materias primas utilizadas en los conjuntos mencionados.

Por otro lado, el resto de las rocas utilizadas no presentan un uso tan recurrente y con las características mencionadas para las rocas silíceas. La cantidad de materias primas utilizadas para la confección de instrumentos y núcleos se reduce notablemente en ambos loci respecto a las encontradas dentro del conjunto que componen los desechos de talla. Sin embargo, la dacita es la materia prima que se asemeja al modo de uso de las rocas silíceas, especialmente en $\mathrm{P}$ 96, lo que permite plantear que estas materias primas presentan características relacionadas con sus propiedades físicas y de disponibilidad en el ambiente que la tornan preferible para la confección de instrumentos en comparación con el resto.

En general, se ha observado un comportamiento que no buscó maximizar el rendimiento de las materias primas, ya que el aprovisionamiento de estas conllevaba un bajo costo. Esto se evidencia a través de los desechos de talla, que exhiben lascas de tamaño grande y muy grande, las que podrían haber sido utilizadas para la confección de instrumentos pero fueron descartadas sin ningún rastro de aprovechamiento visible. Lo mismo ocurre con los núcleos, los cuales fueron descartados, en su mayoría, con tamaños que permitían seguir siendo usados y en estado entero. La forma de estos, en su mayoría expeditivas (Wallace \& Shea, 2006), permite plantear que no se estaba buscando formas base planificadas y por lo tanto posibles de ser conservadas. La maximización de la materia prima no habría constituido una de las principales preocupaciones de estos grupos, por lo menos en cuanto a las que son de origen inmediatamente disponibles. Sin embargo, debe destacarse que se ha detectado la presencia de talla bipolar reflejada en una pequeña proporción de los desechos de talla provenientes de ambas concentraciones. En P 37 se observaron este tipo de lascas sobre calcedonia, materia prima que parece no ser de origen local y también sobre silice.

Otra característica que podría relacionarse con un uso más económico de las materias primas es la confección de varios filos por pieza (Jeske, 1989). Esta característica se ha hallado en algunos instrumentos, principalmente confeccionados sobre sílice. Así, esta materia prima vuelve a aparecer como aquella más intensamente explotada, como ya se había advertido a partir de la variabilidad de tipos de lasca, de talones y bulbos y del uso de la técnica bipolar. Es pertinente señalar que la presencia de más de un filo por pieza fue hallada en un bajo porcentaje de artefactos formatizados en ambas concentraciones analizadas. Asimismo, la presencia de bifaces, usados tanto como formas base de instrumentos y como instrumentos en sí mismos, manufacturados sobre esta materia prima en P 37 abona a la idea de un uso intenso y además ayuda a mostrar el uso de estrategias tecnológicas combinadas por parte de los grupos humanos estudiados que se planteó más arriba.

\section{La inversión energética}

en los instrumentos líticos

La baja inversión energética y el uso poco económico de las materias primas parece ser la estrategia que guió la manufactura de los núcleos. 
Sin embargo, el conjunto lítico aquí analizado presenta algunas características que no responden a este tipo de estrategia.

Por un lado, los artefactos formatizados que componen los conjuntos de ambos loci, como son los artefactos de formatización sumaria, raederas y raspadores, representan instrumentos que implican una baja inversión energética (Escola, 2004) y un escaso aprovechamiento de las materias primas, ya que la gran mayoría de los filos fueron confeccionados con retoques y microrretoques marginales unifaciales (Aschero, 1975, 1983), lo que generó filos de muy poca extensión sobre las caras de los instrumentos. Por otra parte, se ha observado un alto porcentaje de descarte de instrumentos con filos activos tanto en P 96 como en $\mathrm{P} 37$, en este último sólo los instrumentos provenientes del contexto de excavación presentan una amplia mayoría de instrumentos embotados. Esto estaría mostrando, una vez más, la baja tendencia hacia la conservación de los instrumentos y de las materias primas, ya que casi todas las herramientas exhiben tamaños grandes, lo cual los volvería aptos para ser reactivadas. En este sentido se puede plantear el uso de los instrumentos de forma expeditiva (sensu Nelson, 1991), ya que los mismos habrían sido confeccionados aplicando una baja inversión de energía y descartados luego del uso independientemente del estado de sus filos y del tamaño de la pieza a pesar de que en la mayoría de los casos habría sido posible seguir usando los filos existentes o bien, mediante tareas de reactivación, extenderles su vida útil.

Esta estrategia expeditiva habría estado complementada con la manufactura de instrumentos de diseño versátiles (Nelson, 1991, Aschero et al. 1995), como lo indica la presencia de más de un filo en algunos instrumentos de los Puntos 37 y 96 y también con la confección y uso de bifaces (P37 RS N=3, P37 EXC y P 96 $\mathrm{N}=0$ ). Estos instrumentos fueron vinculados con la conservación y maximización de la materia prima (Kelly, 1988; Jeske, 1989; Nelson, 1991). Sin embargo, debe destacarse que los signos que apuntan hacia un estrategia del tipo conservada y los comportamientos tendientes hacia la maximización del rendimiento de la materia prima son los menos frecuentes en todo el conjunto tecnológico de los Puntos 37 y 96, es decir, que esta estrategia sería la menos implementada en este sector por los grupos humanos. La baja representación de los bifaces en estos conjuntos podría estar indicando que los cazadores-recolectores sabían que en esta zona la materia prima era abundante y de calidad apta para la talla y a su vez, que el lugar donde encontrarían la materia prima sería el mismo que en el que los instrumentos confeccionados a partir de la misma serían utilizados (Kelly, 1988).

Una mención aparte merecen los filos naturales con rastros complementarios. Este tipo de artefacto no formatizado pero con presencia de rastros de uso, que informa sobre una muy baja inversión energética (Escola, 2004), ha sido identificado en P 96 sobre un instrumento de dacita que también exhibe dos filos más de distinto grupo tipológico, un filo de raspador y otro de artefacto de formatización sumaria. La dacita es la materia prima más utilizada para la confección de instrumentos en este Punto, por lo que la producción de producir más de un filo sobre la misma pieza podría estar dando cuenta de la búsqueda de maximización de la materia prima (Jeske, 1989), como ya se comentó previamente. Lo que debe destacarse en relación a esta pieza es que apoya la idea de la baja inversión energética puesta en la manufactura de los instrumentos.

A partir de las variables analizadas en los instrumentos provenientes de ambos loci es posible plantear que el tipo de conducta predominante en la confección de los mismos tendía a la baja inversión de energía. Esta interpretación es coincidente con lo propuesto en relación al análisis de los desechos de talla y los núcleos.

\section{El conjunto tecnológico lítico y los pinnípedos}

En una sección precedente se ha presentado la información conocida sobre las actividades relacionadas con el aprovechamiento de los recursos bióticos en los Puntos 37 y 96. Se ha observado que el taxón dominante en ambas concentraciones es el pinnípedo y se han reconocido las dos especies: Otaria flavescens y Arctocephalus australis, siendo esta última la predominante en P 37 (Muñoz et al. 2013). Una diferencia destacable entre ambos loci es la mayor cantidad de individuos inmaduros en P 96, lo que estaría indicando una preferencia por la explotación 
de presas más indefensas o poco agresivas y una baja preocupación por el cuidado del recurso (Cruz et al. 2011a; Muñoz et al. 2013). En esta cuestión, el comportamiento respecto al cuidado de los recursos es equiparable al observado en el conjunto tecnológico, evidenciado por la tendencia hacia el "derroche" de la materia prima.

A partir de la predominancia de individuos inmaduros y especialmente por la presencia de cachorros de hasta 1,5 meses de edad, se ha planteado que es posible que, para el momento que se está considerando, los grupos humanos hayan estado explotando un apostadero reproductivo inexistente actualmente en Punta Entrada o en sus alrededores (Cruz et al. 2010b). La presencia de este grupo etario también muestra que la época del año en la que los cazadores-recolectores estarían ocupando esta zona sería principalmente el verano austral (Cruz et al. 2010b). Ambas situaciones permiten plantear que estos grupos conocían el lugar y las oportunidades que éste les ofrecía, lo que daría cuenta de la posibilidad de emplear una estrategia tecnológica del tipo expeditiva dada la predictibilidad de los recursos bióticos y de la materia prima necesaria para la confección de los instrumentos.

La abundancia y accesibilidad de los pinnípedos y la alta proporción en la explotación de individuos inmaduros y por lo tanto más indefensos, en P 96 se vería reflejada en la manufactura de instrumentos con baja inversión energética y características más bien del tipo expeditivas. No se han observado en este Punto ni en P 37 evidencias de instrumentos confiables que muestren la necesidad de los cazadores-recolectores por elaborar herramientas que ofrezcan la certidumbre de que no fallarán al momento del uso y que evidenciarían un alto costo en la pérdida del recurso buscado.

La tendencia general hacia el manejo poco cuidadoso de ambos tipos de recursos estaría relacionada a una situación que involucra un bajo nivel de riesgo por lo que resulta esperable que la tecnología actúe en consecuencia y se manifieste como un conjunto en el que predominan los comportamientos con poca necesidad de ser planificados y con poca inversión de tiempo en las tareas de manufactura, es decir, comportamientos tendientes hacia una estrategia expeditiva (sensu
Nelson 1991).

Merece mencionarse la falta de evidencias de herramientas aptas para la caza de estos animales en los conjuntos aquí estudiados, ya que si bien existen otros sectores de la costa meridional en los que tampoco se han registrado este tipo de herramientas (Caracotche et al. 2008), existe otra gran parte del registro costero patagónico en los que sí se han recuperado arpones y rompecráneos (Castro et al. 2000; Franco et al. 2010). Es posible que estos instrumentos al ser más costosos no hayan sido descartados en estos loci, que al parecer habrían sido de ocupación estacional y que se los haya conservado y mantenido para futuros usos. En Punta Entrada se han detectado unas pocas piezas que sí habrían servido para la caza de los pinnípedos, como son el caso de dos arpones hallados en el Punto 35 y algunos posibles rompecráneos encontrados a lo largo de la localidad arqueológica (Cruz et al. 2011a, coms. pers. 2012). El registro zooarqueológico muestra evidencias indirectas del posible uso de este tipo de artefactos, como son las marcas de machacado (Cruz et al. 2011a, 2015; Cañete Mastrángelo \& Muñoz, 2015). En el caso de comprobarse la existencia de rompecráneos en otros Puntos de Punta Entrada, esta situación podría estar marcando la práctica de diferentes tareas en los distintos sectores. Las concentraciones aquî analizadas exhiben principalmente instrumentos aptos para el procesamiento de las carcasas, como son las raederas y los raspadores, situación que se ve reforzada por el tipo de marcas de procesamiento que presentan los huesos como fue observado para el caso de P 37 en Cañete Mastrángelo y Muñoz (2015).

Como se explicó previamente, en ambos loci se han hallado evidencias de la realización de actividades relacionadas tanto con todas las etapas de la reducción lítica. Estas actividades podrían haber estado acompañadas con las tareas ya aludidas relacionadas al procesamiento de los pinnípedos manifestadas por los instrumentos mencionados más arriba y por los restos de las carcasas allî recuperados. Las observaciones efectuadas en los restos óseos recuperados en las mismas cuadrículas de las que provienen los materiales líticos de P 37 indican una importancia de las huellas de corte y machacado que se distribuyen en el esqueleto axial 
y apendicular, lo cual sugiere el procesamiento completo de las presas, es decir la desarticulación de las carcasas en porciones y la obtención de tejidos blandos (Cañete Mastrangelo et al. 2013).

\section{CONCLUSIÓN}

En este trabajo se ha presentado la discusión sobre las estrategias tecnológicas llevadas a cabo por los grupos cazadores-recolectores de Punta Entrada durante el Holoceno tardío. Se ha observado que la estrategia predominante es la expeditiva y que en las concentraciones estudiadas se habrían estado desarrollando todas las etapas de la secuencia de reducción lítica. Es destacable que en este caso no se hayan recuperado instrumentos relacionados a la caza de pinnípedos como podría ser esperable dada la abundancia de restos de estos animales en los Puntos 37 y 96. En el futuro se deberá ampliar el tipo de sitio estudiado a fin de evaluar la presencia de este tipo de herramientas en la localidad.

\section{AGRADECIMIENTOS}

A Mariana Carballido Calatayud y A Sebastián Muñoz. A Isabel Cruz y M. Soledad Caracotche. A Víctor López (Ea. Monte Entrance). A la Municipalidad de Puerto Santa Cruz que brindó apoyo logístico. A Adriana Pretto, Carolina Moreno, Patricia Lobbia, Elio Durán, Mariela Arriagada, Santiago Chorolque, Laura Fraschina, Antonela Marozzi, Aldana Calderón, M. Belén Cipitelli por su asistencia en las tareas de campo y laboratorio. A los evaluadores externos que gracias a sus comentarios y sugerencias ayudaron a mejorar este trabajo. Al Instituto Nacional de Antropología y Pensamiento Latinoamericano. Este trabajo es un resultado de los proyectos PIP/ CONICET (CONICET/PIP 112-201201-00359), SECyT UNC Res. 162 y UNPA (29A/302).

\section{BIBLIOGRAFÍA}

Andredsky, JR., W. (1994). Material availability and the organization of technology. American Antiquity, 59(1), 21-34.

Aragón, E., \& Franco, N. V. (1997). Características de rocas para la talla por percusión y propiedades petrográficas.
Anales del Instituto de la Patagonia, Serie Ciencias Humanas, 25,87-199.

Aschero, C. A. (1975). Ensayo para una clasificación morfológica de los artefactos líticos aplicada a estudios tipológicos comparativos. Informe al CONICET. Ms.

Aschero, C. A. (1983). Ensayo para una clasificación morfológica de los artefactos líticos aplicada a estudios tipológicos comparativos. Informe al CONICET. Revisión 1983. Ms.

Aschero, C., \& Hocsman, S. (2004). Revisando cuestiones tipológicas en torno a la clasificación de artefactos bifaciales. En D. Loponte, D. Acosta, \& M. Ramos (Comp.), Temas de Arqueología. Análisis lítico. (pp. 7-26). Buenos Aires: Talleres gráficos del Departamento de Publicaciones e Imprenta, dependiente de la Secretaría de Extensión Universitaria de la Universidad Nacional de Luján,

Aschero, C., Moya, L., Sotelos, C., \& Martínez, J. (1995). Producción lítica en los límites del bosque cordillerano: el sitio Campo Río Roble 1 (Santa Cruz, Argentina). Relaciones de la Sociedad de Antropología, XX, 205-238.

Bellelli, C., Guraieb, A. G., \& García, J. A. (1985). Propuesta para el análisis y procesamiento por computadora de desechos de talla lítica (DELCO- desechos líticos computarizados). Arqueología contemporánea, Vol. II, 1, 36-56.

Binford L. (1979). Organization and formation process: looking at curated technologies. Journal of Anthropological Research, 35(3), 255-273.

Borrazzo, K. 2006. Tafonomía lítica en dunas: una propuesta para el análisis de los artefactos líticos. Intersecciones en Antropología, 7, 247-261.

Borrero, L. A., Barberena, R. , Franco, N. V., Martín, F. M., Caracotche, S., Manzi, L., Charlín, J., \& Borrazo, K. (2008). Plan de monitoreo del Parque Nacional Monte León. La información de superficie. En I. Cruz \& S. Caracotche (Eds.), Arqueología de la costa patagónica. Perspectivas para la conservación. Capítulo 10. (pp. 160-172). Río Gallegos: Universidad Nacional de la Patagonia Austral.

Bousman, C. B. (2005). Coping with risk: Later Stone Age technological strategies at Blydefontein Rock Shelter, South Africa. Journal of Anthropological Archaeology, 24, 193-226.

Bradbury, A. P., \& Carr, P. J. (1999). Examining stage and continuum models of flake debris analysis: an experimental approach. Journal of Archaeological 
Science, 26, 105-116

Buc, N., \& Cruz, I. (2012). El aprovechamiento de la fauna como instrumental óseo en la costa al sur del río Santa Cruz. Las colecciones de Punta Entrada y Parque Nacional Monte León (provincia de Santa Cruz, Argentina). En: trabajo presentado en II Encuentro Latinoamericano de Zooarqueología, Santiago de Chile, 29 de mayo al 1 de junio de 2012. Chile.

Cañete Mastrángelo, D. S. (2015). Análisis comparativo del uso de obsidianas en Punta Entrada y Parque Nacional Monte León, Santa Cruz (Argentina). Trabajo presentado en las X Jornadas de Jóvenes investigadores en Ciencias Antropológicas, Instituto Nacional de Antropología y Pensamiento Latinoamericano, Buenos Aires.

Cañete Mastrángelo, D. S., \& Muñoz, A. S. (2015). El procesamiento de pinnípedos en $\mathrm{P}$ 37, desembocadura del río Santa Cruz, Patagonia Meridional. Cuadernos del Instituto Nacional de Antropología y Pensamiento Latinoamericano 24(1), 131-148.

Cañete Mastrángelo, D. S., Muñoz, S., \& Pretto, A. (2013). El procesamiento de pinnípedos en P37, desembocadura del río Santa Cruz, Patagonia Meridional. En J. R. Bárcena \& S. E. Martín (Eds.), Libro de resúmenes, XVIII Congreso Nacional de Arqueología Argentina (pp. 556). La Rioja: Instituto de Ciencias Humanas, Sociales y Ambientales CONICET.

Caracotche, M. S., Carballo Marina, F., Belardi, J. B., Cruz, I., \& Espinosa, S. (2008). El registro arqueológico del Parque Nacional Monte León (Santa Cruz): un enfoque desde la conservación. En I. Cruz \& S. Caracotche (Eds.), Arqueología de la costa patagónica. Perspectiva para la conservación. Capítulo 9 (pp. 146-158). Río Gallegos: Universidad Nacional de la Patagonia Austral.

Cardillo, M. (2009). Variabilidad en la manufactura y diseño de artefactos en el área costera patagónica. Un enfoque integrador. Tesis Doctoral. Facultad de Filosofía y Letras, Universidad de Buenos Aires. Ms

Carr, P. J. (1994a). The Organization of Technology: Impact and potencial. En J. Carr, Philip (Ed.), The Organization of North American prehistoric chipped stone tool technologies (pp. 1-9). Michigan: Archaeological Series 7, International Monographs in Prehistory.

Carr, P. J. (1994b). Technological Organization and the Prehistoric Hunter-Gatherer Mobility: Examination of the Hayes Site. En P. J. Carr (Ed.), The Organization of North American prehistoric chipped stone tool technologies (pp. 35-45). Michigan: Archaeological Series 7, International Monographs in Prehistory.

Castro, A., Moreno, J. E., Martinelli, K., \& Pepe, F. (2000).
Restos faunísticos, artefactos líticos: más información sobre la costa norte de Santa Cruz. En Desde el País de los Gigantes. Perspectivas arqueológicas en Patagonia (Actas de las IV Jornadas de Arqueología de la Patagonia, Río Gallegos, 2 al 6 de noviembre de 1998) (pp. 551-561).Tomo II. Río Gallegos: Universidad Nacional de la Patagonia Austral.

Charlín, J. 2005. Utilización de materias primas líticas en el campo volcánico Pali Aike (Pcia. Santa Cruz, Argentina). Una primera aproximación a partir del análisis de los núcleos. Werken, 7, 39-55.

Civalero, M. T., \& Franco, N. V. (2003). Early human occupations in western Santa Cruz province, southernmost South America. Quaternary International, 109-110, 77-86

Cruz, I., Ercolano, B., Cañete Mastrángelo, D. S., Caracotche, M. S., \& Lemaire, C. R. (2015). Tafonomía y procesos de formación en P 96 (Punta Entrada, Santa Cruz, Argentina). Cuadernos del Instituto Nacional de Antropología y Pensamiento Latinoamericano 24 (1), 95-114.

Cruz, I., Muñoz, A. S., \& Caracotche, M. S. (2010a). Un artefacto en asta de huemul (Hippocamelus bisulcus) en depósitos arqueológicos de la costa atlántica. Implicancias para la movilidad humana y la distribución de la especie. Magallania, 38(1), 287-294.

Cruz, I., Muñoz, A. S., \& Lobbia, P. (2010b). Zooarqueología al sur del río Santa Cruz (Patagonia argentina). Los restos de fauna de P 96 (Punta Entrada) y CL 1 (P. N. Monte León). En: (Eds. Bárcena, J. Roberto y Horacio Chiavazza) Arqueología Argentina en el Bicentenario de la Revolución de Mayo (Actas del XVII Congreso Nacional de Arqueología Argentina, Mendoza, 11 al 15 de Octubre de 2010). Tomo I (pp. 315-320). Mendoza: Universidad Nacional de Cuyo.

Cruz, I., Muñoz, A. S., \& Lobbia, P. (2011a). La explotación de recursos marinos en la costa de Patagonia continental: los restos de vertebrados en depósitos de Punta Entrada y Monte León (Santa Cruz, Argentina). Revista de Estudios Maritimos y Sociales, 4(4), 31-41.

Cruz, I., Caracotche, M. S, Stern, C., Muñoz, A. S., Suby, J. A., Lobbia, P. A., Ercolano, B., \& Cañete Mastrángelo, D. S. (2011b). Obsidianas y otros indicadores de circulación y uso del espacio en Punta Entrada y P. N. Monte León (Santa Cruz, Argentina). En: Libro de resúmenes VIII Jornadas de Arqueología de la Patagonia. San Rafael: Museo de Historia Natural de San Rafael.

Del Valle, M., \& Kokot, R. (1998). Geomorfología y aspectos ambientales del área de Puerto Santa Cruz, Argentina. 
En Actas del X Congreso Latinoamericano de Geología y VI Congreso Nacional de Geología Económica. Vol. 1 (pp. 346). Buenos Aires.

Cruz, I, Muñoz, A. S., Ercolano, B., Lemaire, C., \& Pretto, A. (2012). La explotación de un apostadero reproductivo de pinnípedos en Punta Entrada (Santa Cruz, Argentina) durante el Holoceno tardío. Libro de Resúmenes, II Encuentro Latinoamericano de Zooarqueología (pp. 88). Santiago de Chile: Universidad de Chile.

Ercolano, B. (2012). Esquema evolutivo de Punta Entrada, desembocadura del río Santa Cruz. Libro de resúmenes, VIII Jornadas Nacionales de Ciencias del Mar. XVI Coloquio de Oceanografía (pp. 106) Comodoro Rivadavia.

Ericson, J. E. (1984). Toward the análisis of lithic production systems. En J. E. Ericson \& Purdy, B. A. (Eds.), Prehistoric quarries and lithic production (pp. 1-9). Cambridge: Cambridge University Press.

Escola, P. S. 2004. La expeditividad y el registro arqueológico. Chungara, Volumen especial, 49-60.

Espinosa, S. (1995). Dr. Scholl y Monsieur Fleur: de talones $y$ bulbos. Cuadernos del Instituto Nacional de Antropología y Pensamiento Latinoamericano, 16, 315-327.

Espinosa, S. (1998). Desechos de talla: tecnología y uso del espacio en el Parque Nacional Perito Moreno (Santa Cruz, Argentina). Anales del Instituto de la Patagonia, Serie Ciencias Humanas, 26, 153-168.

Espinosa, S. (2002). Estrategias tecnológicas líticas y uso del espacio en momentos tardíos en el Parque Nacional Perito Moreno (Santa Cruz). Tesis para optar al grado de Doctor en Filosofía y Letras. Facultad de Filosofía y Letras. Universidad de Buenos Aires. Ms.

Fidalgo, F., \& Riggi, J. C. (1970). Consideraciones geomorfológicas y sedimentológicas sobre los rodados patagónicos. Revista de la Asociación Geológica Argentina, XXV(4), 430-443.

Franco, N. V. (2004). La organización tecnológica y el uso de escalas espaciales amplias. El caso del Sur y Oeste del lago Argentino. En D. Loponte, A. Acosta \& M. Ramos (Comp.), Temas de Arqueología. Análisis lítico (pp. 101-145). Buenos Aires: Talleres gráficos del Departamento de Publicaciones e Imprenta, dependiente de la Secretaría de Extensión Universitaria de la Universidad Nacional de Luján.

Franco, N. V., \& Cirigliano, N. A. (2009). Materias primas y movilidad humana entre las cuencas de los ríos Santa Cruz y Chico (provincia de Santa Cruz, Argentina): primeros resultados. En M. Salemme, F. Santiago, M.
Álvarez, E. Piana, Vázquez, M., \& M. Mansur (Comp.), Arqueología de Patagonia: una mirada desde el último confín. Tomo I (pp. 361-368). Ushuaia: Editorial utopías.

Franco, N. V., Zubimendi, M. A., Cardillo, M., \& Guarido, A. L. (2010). Relevamiento arqueológico en Cañadón de los Mejillones (sur de la desembocadura del río Santa Cruz, Argentina): primeros resultados. Magallania, 38 (1), 269-280.

Frank, A. D., Skarbun, F., \& Paunero, M. F. (2007). Hacia una aproximación de las primeras etapas de reducción lítica en el Cañadón de la Mina, localidad arqueológica La María, meseta central de Santa Cruz, Argentina. Magallania, 35(2), 133-144.

Guraieb, A. G., \& Espinosa, S. (1998). La secuencia de producción lítica del alero Dirección Obligatoria: algunas dimensiones del problema. Actas y Memorias del XI Congreso Nacional de Arqueología Argentina ( $8^{a}$ parte). Revista del Museo de Historia Natural de San Rafael, XX(1/4), 159-171.

Jeske, R. (1989). Economies in raw material use by prehistoric hunter-gatherers. En R. Torrence (Ed.), Time, energy and Stone tools (pp.34-45). Cambridge: Cambridge University Press,.

Kelly, R. L. (1988). The three sides of biface. American Antiquit, 53(4), 717-734.

Kokot, R. 2004. Erosión en la costa patagónica por cambio climático. Revista de la Asociación Geológica Argentina, 59(4), 715-726.

Macdonald, D. H. (2008). The role of lithic raw material availability and quality in determining tool kit size, tool function, and degree of retouch: a case study from Skink Rockshelter (46NI445), West Virginia. En W. Jr. Andrefsky (Ed.), Lithic technology: measures of production, use, and curation (pp. 216.232). New York: Cambridge University Press.

Meltzer, D. J. (1989). Was Stone exchanged among Eastern North American Paleoindians? En C. J. Ellis \& J. Lothrop (Eds.), Eastern Paleoindian lithic resource use (pp. 11-39). Boulder: Westview Press.

Muñoz, A. S., Cruz, I., \& Caracotche, M. S. (2009). Cronología de la costa al sur del río Santa Cruz: Nuevas dataciones radiocarbónicas en Punta Entrada y Parque Nacional Monte León (provincia de Santa Cruz, Argentina). Magallania, 37(1), 19-38.

Muñoz, A. S., Cruz, I., Lemaire, C. R. \& Pretto, A. (2013). Los restos arqueológicos de pinnípedos de la desembocadura del río Santa Cruz (Punta entrada, costa atlántica de Patagonia) en perspectiva regional. 
En A. F. Zangrando, Barberena, R., Gil, A., Neme, G., Giardina, M., Luna, L., Otaola, C., Paulides, S., Salgán, L., \& A. Tivoli (Comp.), Tendencias Teórico Metodológicas y Casos de Estudio en la Arqueología Patagónica (pp. 459-467). Buenos Aires: Museo de Historia Natural de San Rafael, Sociedad Argentina de Antropología e Instituto Nacional de Antropología y Pensamiento latinoamericano.

Nami, H. (2006). Experiments to explore the Paleoindian flake-core technology in southern Patagonia. En J. Apel \& K. Knutsson (Eds.), Skilled Production and Social Reproduction. Aspects of Traditional StoneTool Technologies. Proceedings of a Symposium in Uppsala, August 20-24, 2003. Capítulo I (pp. 69-80). Sweden: Societas Archaeologica Upsaliensis.

Nelson, M. (1991). The study of technological organization. En M. Schiffer (Ed.), Archaeological method and theory. Vol. 3 (pp. 57-100). Tucson: University of Arizona Press.

Odell, G. (1994). Assessing hunter-gatherer mobility in Illinois Valley: exploring ambiguous results. En P. J.
Carr (Ed.), The Organization of North American prehistoric chipped stone tool technologies (pp. 7086). Archaeological Series 7, Michigan: International Monographs in Prehistory.

Paulides, L. S. (2006). El núcleo de la cuestión. El análisis de los núcleos en los conjuntos líticos. En C. Pérez de Micou (Ed.), El modo de hacer las cosas: artefactos y ecofactos en arqueología (pp. 67-100). Buenos Aires: Universidad de Buenos Aires.

Stern, C., Caracotche, S., Cruz, I., \& Charlín, J. (2012). Obsidiana gris porfírica calco-alcalina del volcán Chaitén en sitios arqueológicos al sur del río Santa Cruz, Patagonia Meridional. Magallania 40(1), 137144.

Suby, J. A., Guichón, R., \& Zangrando, A. F. (2009). El registro biológico de la costa meridional de Santa Cruz. Revista Argentina de Antropología Biológica, 11(1), 109124.

Wallace, I. J., \& Shea, J. J. (2006). Mobility patterns and core technologies in the Middle Paleolithic of the Levant. Journal of Archaeological Science, 33, 1293-1309. 